\title{
DOES CLOSED INTRAMEDULLARY INTERLOCKING NAILING IN PATIENTS WITH HUMERAL SHAFT FRACTURES HAS ADVANTAGES: EVALUATION THROUGH A CLINICAL STUDY
}

\author{
SAI PAVAN KUMAR MURARI*, NAGAM KIRTHI CHANDRA, ANIRUDH PHANI BHARGAV K, \\ SHANTHAN REDDY PALVAI
}

Department of Orthopedics, Apollo Institute of Medical Sciences and Research, Hyderabad, Telangana, India. Email: pavan.murari@gmail.com

Received: 02 December 2016, Revised and Accepted: 17 December 2016

\section{ABSTRACT}

Objective: Intramedullary interlocking nail fixation (IINF) for the fracture shaft humerus (FSH) offers good clinical outcome. Evaluating the functional outcome of IINF in FSH and assessing the complications of the technique, time taken for fracture consolidation, and union rates were the objectives.

Methods: Adult patients with a clinical diagnosis of diaphyseal fracture of humerus were assessed clinically and radiologically for the functional outcome of IINF in FSH. Functional outcome of shoulder and elbow considered together was graded as excellent, moderate, and poor. Daily assessment was done along with active physiotherapy. All were followed up at monthly intervals for 6-12 months or till the union of fracture. Radiological assessment was done at immediate post-operative period, at months 1, 3, 6, 9, and 12 months.

Results: 30 patients (males $n=24,80 \%)$ with a mean( \pm standard deviation) age of $39( \pm 13.31)$ years were included. Road traffic accident was the frequent cause $(n=18,60 \%)$. Indirect injury was the cause in $66.66 \%$ patients. Middle $1 / 3^{\text {rd }}$ of shaft of humerus was fractured in $53.33 \%$ patients. $10(33.3 \%)$ patients each had oblique fracture and transverse fracture, respectively; comminuted fracture was seen in another $26.6 \%$ patients. Radial nerve palsy (10\%) was the frequent associated injury of the total nine. The overall functional outcome was excellent in $80 \%$, moderate in $16.6 \%$, and poor in $3.3 \%$ patients. Postoperatively, nonunion, superficial infection and shoulder stiffness was seen in one patient each.

Conclusion: IIFN is an excellent, least invasive surgical option for FHS with early fracture consolidation and better union rates.

Keywords: Fracture shaft humerus, Functional outcome, Intramedullary interlocking nail fixation, Nonunion, Shoulder stiffness, Superficial infection. (C) 2017 The Authors. Published by Innovare Academic Sciences Pvt Ltd. This is an open access article under the CC BY license (http://creativecommons. org/licenses/by/4. 0/) DOI: http://dx.doi.org/10.22159/ajpcr.2017.v10i3.16439

\section{INTRODUCTION}

The goal of humeral shaft fracture management aims at achieving union of fracture ends with an acceptable humeral alignment and restoration of function to that before fracture. Treatment option is based on the patient and fracture characteristics (patient's age, the presence of associated injuries, soft tissue status, and fracture pattern) [1]

Conservative management of fractures of humeral diaphysis yields high rates of fracture union and good functional outcome in many patients. Surgery is considered only in selective cases of humerus fracture in polytrauma patient, fractures with unacceptable alignment after closed reduction, segmental fracture, pathologic fracture, radial nerve injury, and radial nerve dysfunction after fracture manipulation, associated vascular injury, open fracture, and floating elbow [1,2].

Complications of external fixation, i.e., pin tract infection, neurovascular injury, tendon and muscle impalement and nonunion, though can be avoided by meticulous operative technique, make this less adopted approach [1,2]. Of two methods of internal fixation, intramedullary fixation is preferred as it offers advantages over plate and screws. In addition, closed nailing technique, without exposing the fracture site preserves the fracture hematoma, which is very much essential for fracture healing [3]. Closed nailing preserves the periosteal blood supply and promotes fracture union by utilizing the osteogenic potential of the pluripotent cells in the fracture hematoma. Thus, closed intramedullary nailing supports the concept of biological fixation [4]. Moreover, closed nailing procedure is associated with fewer complications such as reduction in blood loss, infection rates, and hospital stay. Most of these reports are from the western and developed countries providing better health-care facilities.
This treatment method has been the subject of controversy since its inception because of concern of damage to medullary circulation, possibilities of fat embolism, complications arising from application of incorrect technique, and lack of understanding of the biomechanical principles of intramedullary interlocking nail fixation (IINF). Hence, we conducted this study in adult Indian patients with fracture shaft humerus (FSH) to study the clinical outcome of the closed intramedullary interlocking nailing (IIN) and its advantages in these patients in a tertiary care hospital that caters to the patients from middle and lower socioeconomic class with less awareness and limited access to health-care facilities.

\section{METHODS}

\section{Patients}

This prospective clinical study was conducted by the Department of Orthopedics of a Tertiary Care Hospital from Telangana state of India. We initiated this study after obtaining Institutional Ethics Committee's approval. Our study is a series of 30 cases of humeral shaft fractures treated with closed IIN over a period of 2-year.

Prospective patients were screened after obtaining written informed consent. We included adult patients of both genders with a clinical diagnosis of diaphyseal fracture of humerus, supported radiologically.

The primary objective of the study was to evaluate the functional outcome of IINF in fracture shaft of humerus. In addition, the pitfalls, complications of interlocking nailing technique, the outcome in terms of time taken for fracture consolidation, union rates were analyzed; role of early rehabilitation was also evaluated. 
We included patients $>19$ years with fracture of humeral shaft from $3 \mathrm{~cm}$ proximal to the olecranon fossa to $2 \mathrm{~cm}$ distal to the surgical neck of the humerus, unacceptable alignment after closed reduction of the fracture, polytrauma patients with humoral shaft fractures and closed fractures including simple, segmental, comminuted, and pathological fractures.

Patients aged $<19$ years were excluded as the physis is still open in them those with humeral shaft fractures involving the proximal and distal ends of the humerus and all open fractures of the humerus were also excluded.

After obtaining history, patients were assessed clinically to evaluate their general condition and local injury. Details were recorded on a preapproved proforma. Fracture site was examined for the signs of fracture. Any associated neurovascular deficit was noted.

Radiographs of the affected arm including shoulder and elbow joints were taken in anteroposterior and lateral views. Blood investigations (complete blood count, blood urea, serum creatinine, blood sugar, human immunodeficiency virus, hepatitis B surface antigen), electrocardiogram and chest X-ray were taken at baseline for preoperative evaluation.

All patients were operated under anesthesia, after a thorough evaluation, and adequate preoperative preparation. A systemic antibiotic (ceftriaxone $1 \mathrm{~g}$ ) and tetanus toxoid (intramuscularly) were given $1 \mathrm{hr}$ before surgery.

Postoperatively, the arm was placed in a sling. Early range of motion exercises for shoulder and elbow were started as soon as operative pain subsided. Emphasis was given to shoulder and elbow range of motion exercise to avoid joint stiffness. In patients without any associated injuries or the injuries did not warrant hospital stay, patients were discharged on $4^{\text {th }}$ or $5^{\text {th }}$ post-operative day, after instructing about the range of motion exercises. Sutures were removed on $14^{\text {th }}$ post-operative day.

\section{Follow-up}

All patients were followed up at monthly intervals for 6-12 months or till the union of fracture. Importance was given to restoration of range of movements of shoulder, elbow and subjective complaints throughout the follow-up period. Radiographs were taken both in anteroposterior and lateral views to check for signs of union at immediate post-operative period, months $1,3,6,9$, and 12 months.

Assessment of patients was done on the basis of clinical and radiological union, range of motion at shoulder, elbow joints and subjective complaints like pain in shoulder and elbow joints.

Functional results were graded by the criteria of Rommens et al., (Table 1) [5].Total functional outcome of both joints (shoulder and elbow) was taken into consideration.

\section{Statistical analysis}

The data were captured on Microsoft-Excel (2007) worksheets after editing for completeness and consistency. Results were expressed as descriptive measures for continuous variables (mean and standard deviation [SD]) and as \%, frequency distribution for categorical variables. Subgroup analysis was carried out based on primary outcome measures. Tables and figures are used as appropriate.

\section{RESULTS}

In this study of 2 years duration, 30 cases of humeral shaft fractures treated by intramedullary nailing were evaluated.

Study population consisted of $24(80 \%)$ males and $6(20 \%)$ females, with a mean \pm SD of $39 \pm 13.31$ years; minimum age was 21 years while maximum was 65 years (Fig. 1)
Laborers and agriculturists $(n=8,26.6 \%)$ were most frequently affected followed by homemakers ( $n=5,16.6 \%$ ) (Fig. 2).

There was no significant difference between the sides affected; right side involvement was seen in 16 (53.4\%) and left in 14 patients (46.6\%).

Road traffic accident was the frequent cause $(n=18,60 \%)$ and rest $(\mathrm{n}=12,40 \%)$ had a history of fall. Indirect injury was the cause in $20(66.66 \%)$ and direct injury in $10(33.33 \%)$ patients.

Middle $1 / 3^{\text {rd }}$ of shaft of humerus was fractured in $16(53.33 \%)$ patients (Fig. 3).

$10(33.3 \%)$ patients had oblique fracture, 10 (33.3\%) patients had transverse fracture, $8(26.6 \%)$ patients had comminuted fracture, and $2(6.6 \%)$ patients had spiral fracture.

Table 2 shows the Association for the Study of Internal Fixation (AO) sub-classification.

$9(30 \%)$ patients had associated injuries; radial nerve palsy $(n=03,10 \%)$ was the frequent associated injury; ipsilateral rib fracture, fracture both bone forearm on the contralateral side, ipsilateral fracture shaft of tibia,

Table 1: Grading of functional outcome

\begin{tabular}{lll}
\hline Grade & ROM shoulder and elbow & Subjective \\
\hline Excellent & $<10^{\circ}$ loss of ROM in direction & None \\
Moderate & $\begin{array}{l}10-30^{\circ} \text { loss of ROM in any } \\
\text { direction }\end{array}$ & Mild \\
Poor & $>30^{\circ}$ loss of ROM in any & Moderate to severe \\
& direction & \\
\hline
\end{tabular}

ROM: Range of motion

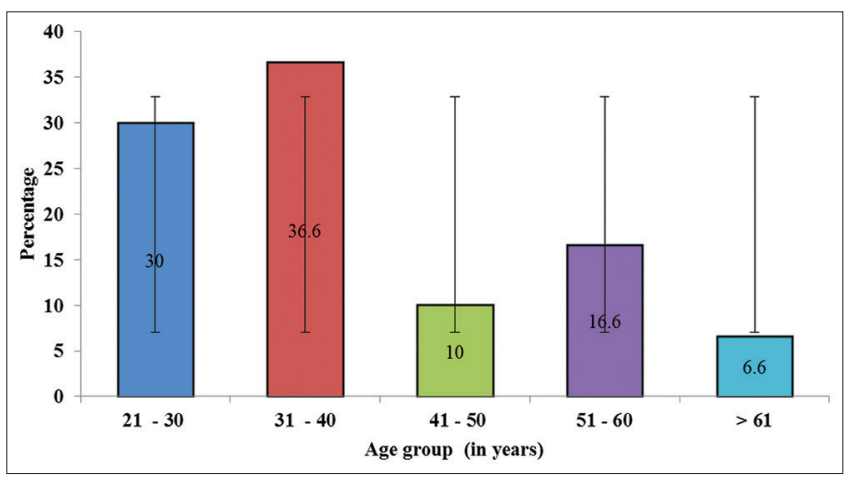

Fig. 1: Age distribution among the study population

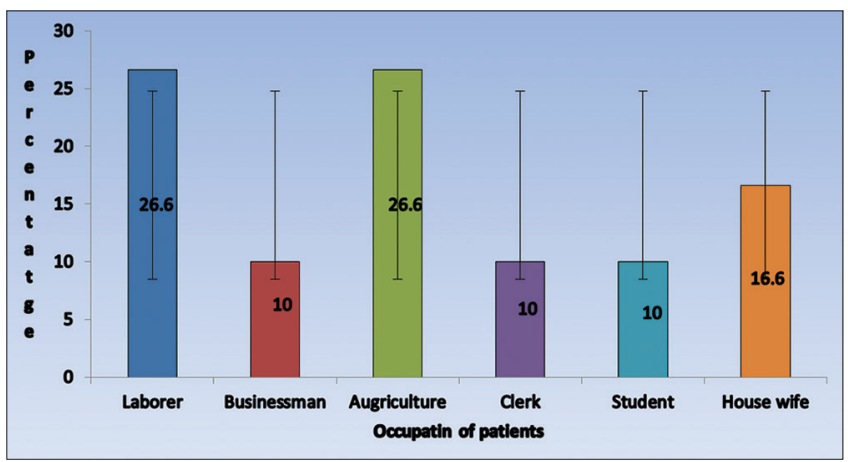

Fig. 2: Occupation of study population $(n=30)$ 


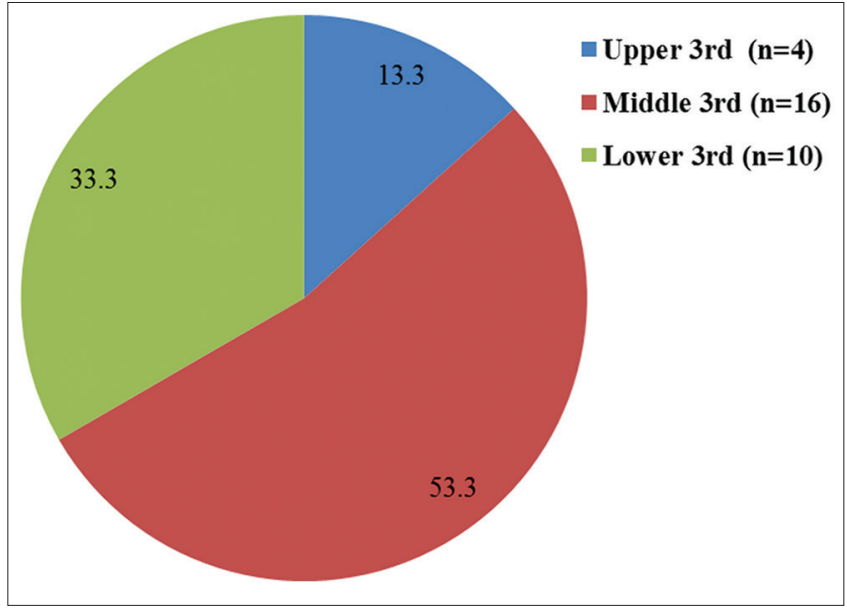

Fig. 3: Site of fracture of shaft of humerus in study population $(n=30)$

mandible fracture, blunt abdominal injury, and head injury were noted in one patient each.

Mean $( \pm \mathrm{SD})$ time interval between occurrence of injury and surgery was $7.5( \pm 2.5)$ days; eighteen $(60 \%)$ patients were operated within a week of trauma while the rest were operated between 8 and 15 days.

All were treated with closed IIN in antegrade manner except $5(16.66 \%)$ cases that required open procedure to treat radial nerve palsy. The procedure was done either under general anesthesia $(n=20)$ or brachial block $(n=10)$.

Closed intramedullary nailing was performed for 25 (83.4\%) patients. These nails were passed in antegrade manner and locked in static mode. $5(16.6 \%)$ patients required open reduction because of associated radial nerve palsy, which was decompressed and the fracture was fixed with interlocking nail in static mode.

\section{Period of immobilization after surgery}

Immediate immobilization (within 3-6 days postoperatively) was advised and implemented for all, except one who was immobilized externally with POP slab for 3 weeks due to pain in the shoulder joint. The mean $( \pm S D)$ period for immobilization was $5.5( \pm 1.5)$ days.

All were followed up postsurgery. The average period of follow-up was 9 months, for a minimum of 6 months, and maximum of 12 months.

The period of fracture union ranged from 10 to 16 weeks with an average period of 13-week. Nonunion was observed in one patient.

Overall functional results were excellent in $80 \%$ patients, moderate in $16.6 \%$ patients, and poor in $3.3 \%$ patients (Table 3 ).

Functional outcome was satisfactory in $24(80 \%)$ patients. Restriction of joint motion was seen in patients who were immobilized for long duration $(n=05,16.66 \%)$

\section{Complications}

There were no pre- or intra-operative complications. Although 3 (10\%) patients suffered additional comminution at fracture site during nail insertion intraoperatively, but did not affect the fracture union.

\section{Post-operative complication}

One $(3.3 \%)$ patient developed superficial infection which subsided with appropriate antibiotics. There was no incidence of deep-seated infection in any.

Three (10\%) patients had nail impingement of proximal end due to incomplete burying into the bone. They had occasional pain in the
Table 2: A0 sub classification of injury $(n=30)$

\begin{tabular}{ll}
\hline Type & Number of patients (\%) \\
\hline A & $2(6.6)$ \\
A1 & $10(33.3)$ \\
A2 & $10(33.3)$ \\
A3 & - \\
B & $4(13.3)$ \\
B1 & $3(10)$ \\
B2 & - \\
B3 & $1(3.3)$ \\
C1 & - \\
C2 & \\
C3 & \\
\hline
\end{tabular}

AO: Arbeitsgemeinschaft für osteosynthesefragen

Table 3: Functional outcome in study population $(n=30)$

\begin{tabular}{lll}
\hline \multirow{2}{*}{ Grade } & $\mathbf{n}(\%)$ & \\
\cline { 2 - 3 } & Shoulder & Elbow \\
\hline Excellent & $24(80.0)$ & $27(90.0)$ \\
Moderate & $5(16.67)$ & $3(10.0)$ \\
Poor & $1(3.3)$ & $0(0)$ \\
\hline
\end{tabular}

shoulder with restriction of terminal $15-20^{\circ}$ of abduction. They had moderate functional outcome.

Shoulder stiffness was observed in one $(3.3 \%)$ patient in whom abduction was affected with a range of $0-90^{\circ}$. This patient complained of severe pain, the cause was unknown. He had poor functional outcome.

Nonunion was seen in one (3.3\%) patient who was fixed in distraction at the fracture site. On follow-up, there were no signs of fracture union. The fracture ended in nonunion. A secondary procedure with autologous bone graft was performed after 9 months, which achieved union later.

\section{DISCUSSION}

Conservative management of fractures of shaft humerus often yield satisfactory therapeutic outcome, operative stabilization is required in few including those with unsatisfactory closed reduction and multiple injuries. Moreover, surgery is preferred by orthopedic surgeons in these patients and also by patients for the rapid relief of symptoms, restoration of joint functions. Invention of newer techniques has made the surgery easier to perform with lesser complications.

Plate osteosynthesis has yielded high success rate but requires extensive dissection with the risk of radial nerve damage and refracture after implant removal. Advantages of intramedullary nailing have made it the choice of surgical treatment [6], but the use of unlocked flexible nails has been complicated by poor rotational stability and slipping of the nails causing joint irritation. Locked nailing overcomes these deficiencies, and results in satisfactory therapeutic outcome. It has been considered the treatment of choice in humeral shaft fractures in the recent past [7]. Thus, we evaluated the clinical outcome and advantages of intramedullary nailing in our patients with FSH.

In our study of 30 patients, $80 \%$ were men and mean age was 39 years; laborers and agriculturists $(n=8,26.6 \%)$ were most frequently affected followed by homemakers $(n=5,16.6 \%)$. All these are attributable to the higher physical activity in these patients.

Males are more prone to have humeral shaft fractures $[6,8,9]$ but few studies did not find any significant gender difference $[5,10,11]$. Mean age ranged between 32 and 48 years [5-6,8-10].

Road traffic accident (RTA) was the most common mode of injury in most of the studies [5,8-10]. RTA (n=18) was the cause in 16 men and 
mean age was 39 years (21-65 years) in these patients. This could be attributed to the increased use of two wheelers for transportation by the population in this age group.

Middle-third of the shaft is the most common location of the fracture $[5,8,9]$ which was seen in our patients too $(53.3 \%)$. We noted that the right extremity was affected in $53.33 \%$ patients.

Reports available have documented humeral shaft fractures of category A of AO classification system $[5,9,11]$. In our study, $73.3 \%$ fractures were of category A of AO classification system.

Associated multiple injuries are frequent with FSH [5,8,9], indicating the degree of trauma in these patients. Our patients $(n=09,30 \%)$ too had associated multiple injuries. Radial nerve injury ( $\mathrm{n}=03,10 \%)$ was the most common injury reported in our patients. Other injuries included ipsilateral rib fracture, fracture both bone forearm on the contralateral side, ipsilateral fracture shaft of tibia, mandible fracture, blunt abdominal injury, and head injury.

Marty et al. [12] reported fracture of middle $3^{\text {rd }}$ of humerus was common $(85.25 \%)$ in their study population. Simple transverse fracture of A3 type was frequent (47.54\%). Radial nerve palsy was seen in $14.75 \%$ before surgery and one patient developed nerve palsy, postoperatively. There was no incidence of infection. Functional outcome was good in $85.42 \%$. Nonunion was the complication seen in $7.14 \%$ [12]

Most of the operative methods for stabilization of humeral shaft fractures have acceptable rates of union. Reported rates of fracture end union have been > 90\% [5,13,14], 96 [15] - 97\% [16] depending on the techniques and procedures followed. Nonunion of fractured ends though less, can be expected $[6,17]$. No incidence of nonunion was reported by few studies $[9,11,18]$. As the flexible intramedullary nails lack rotational control, they are frequently associated with nonunions. More rigid locked intramedullary nails have better rotational control than flexible nails, which theoretically should decrease the frequency of nonunion.

Time taken for union of fractures is clinically important following which the patient can resume normal activities. Again, there is a varied period stated by different studies. Very short period of 3.2 months have been reported by Crates and Whittle [8], while Lin reported 8.6 weeks [9]. Longer time of 13.7 weeks and 18 weeks were reported by Rommens et al. [5] and Ozturkmen et al., respectively [7].

In our series, $96.6 \%$ fractures united with a mean time for union of 13 weeks (range 10-16 weeks), which is comparable with the available data. We attribute early mobilization, fracture consolidation and higher union rates to nailing technique, which preserves fracture hematoma and use of unreamed nailing which preserves the endosteal vascularity promoting early fracture union.

Proximity of radial nerve to the humeral shaft makes it prone for iatrogenic injury during any operative approach to the humerus. There have been reports of iatrogenic radial nerve injury, however, with varied incidence between $0 \%$ and $3.3 \%[8,9,15,17-23]$. There was no transient iatrogenic radial nerve palsy reported in our study.

Iatrogenic fracture comminution is frequently encountered issue in these patients; reported to be $0-3$ in previous studies $[5,8,9,24]$. In our study, we encountered three cases of intraoperative fracture comminution but this did not interfere with fracture healing and all these fractures united well within 4 months.

Infection is a common postsurgical complication associated with any operative procedures, more frequently with those involving humerus, because of the rich vascular supply and large soft tissue surrounding the humerus. Incidence are seen varies with the procedure adopted, higher incidence with plate fixation [19,23,25,26]; intramedullary nail fixation is associated with less incidence, however, even open procedures have reported lesser incidence [15,21,22,27]. Most of them occurred after open nailing and with nailing in open fractures. Incidence of infection is more with open surgeries compared to closed intramedullary nailing [28], which may require removal of nail and appropriate antibiotic therapy [11].

Few reports of zero occurrence of infection have also been $[5,8,17-18,22,29]$. Robinson et al. [22] reported $6.7 \%$ infection in humeral shaft fractures treated with seidel nailing. In our study, one case of the fractures got infected (superficial), which subsided with appropriate antibiotics. This we attribute to open method of nailing.

Potential deleterious effects of antegrade humeral nailing on shoulder function have been debated the most. This can be due to impingement of proximal nail tip or proximal locking screw due to adhesive capsulitis or due to rotator cuff tears. In most of the studies with antegrade nailing, $80-95 \%$ of patients regained their normal shoulder function $[8,24,30]$. In our study, $80 \%$ patients had excellent shoulder function with near normal range of motion of shoulder while $16.6 \%$ had moderately good shoulder function. These patients had impingement of proximal end of the nail. One patient had severe shoulder stiffness with significant restriction of shoulder motion.

Good therapeutic outcome considered excellent or good was obtained in $79-85 \%$ patients who were operated with the intramedullary nailing technique [7,11,17]. Ozturkmen et al. [7] reported apart from excellent therapeutic outcome, moderate in $13 \%$, and poor in $8 \%$ patients. Our results are comparable to that of Ozturkmen et al. [7] with excellent outcome in $80 \%$, moderate in $16.67 \%$, and poor in $3.3 \%$ patients.

Post-operative early mobilization of the shoulder and elbow was very critical in attaining full range of movements in these patients. The movements and the functional ability of the shoulder depend on the patient's adherence to rehabilitation program and early intensive physiotherapy hastened the recovery of shoulder function.

Closed intramedullary nailing with an interlocking nail is a safe and reliable method of treating humeral shaft fractures. Among available surgical modalities, closed nailing is the least invasive surgical technique and has the least chance of post-operative infection. It reduces the duration of the hospital stay. Complications like nonunion can be avoided by intraoperative compression and avoiding distraction at fracture site. Certain technical aspects like burying the proximal nail end at the entry portal are essential in avoiding impingement and to gain better shoulder function.

\section{CONCLUSION}

Closed intramedullary nailing is an excellent, least invasive surgical option available to manage humeral shaft fractures with early fracture consolidation and better union rates. It decreases the hospital stay, provides early rehabilitation and reduces the morbidity. It is ideal in patients with polytrauma and osteoporosis. Early intensive physiotherapy hastens the recovery of shoulder function.

\section{ACKNOWLEDGMENTS}

We acknowledge all patients who participated in this study. We thank the management of the institution who supported us by extending their guidance. We thank Dr. Latha MS of Anulekha writers for editing this manuscript.

\section{REFERENCES}

1. Balfour GW, Mooney V, Ashby ME. Diaphyseal fractures of the humerus treated with a ready-made fracture brace. J Bone Joint Surg Am 1982;64(1):11-3

2. Thakur AJ. The Elements of Fracture Fixation. (eBook). $2^{\text {nd }}$ ed. New Delhi: Elsevier India; 2007. 
3. Sahu RL, Ranjan R, Lal A. Fracture union in closed interlocking nail in humeral shaft fractures. Chin Med J (Engl) 2015;128(11):1428-32.

4. Chandler RN. Principles of internal fixation. In: Rockwood CA Jr, editor. Rockwood and Green's Fractures in Adults. $4^{\text {th }}$ ed., Vol. 1. Ch. 3. Philadelphia, PA: Lippincott-Raven; 1996. p. 159.

5. Rommens PM, Verbruggen J, Broos PL Retrograde locked nailing of humeral shaft fractures. A review of 39 patients. J Bone Joint Surg Br 1995;77(1):84-9.

6. Kesemenli CC, Subasi M, Arslan H, Necmioglu S, Kapukaya A. Comparison between the results of intramedullary nailing and compression plate fixation in the treatment of humerus fractures. Acta Orthop Traumatol Turc 2003;37(2):120-5.

7. Ozturkmen Y, Dogrul C, Dogan A, Karli M. Locked intramedullary nalling of humeral shaft fractures. Ulus Travma Derg 2002;8(3):164-9.

8. Crates J, Whittle AP. Antegrade interlocking nailing of acute humeral shaft fractures. Clin Orthop Relat Res 1998;(350):40-50.

9. Lin J. Treatment of humeral shaft fractures with humeral locked nail and comparison with plate fixation. J Trauma 1998;44(5):859-64.

10. Tingstad EM, Wolinsky PR, Shyr Y, Johnson KD. Effect of immediate weight bearing on plated fractures of the humeral shaft. J Trauma 2000;49(2):278-80.

11. Kelsch G, Deffner P, Ulrich C. Seidel humerus intramedullary nailing. Clinical results of 100 surgeries. Unfallchirurg 1997;100(2):111-8.

12. Marty B, Käch K, Friedl HP, Trentz O. Intramedullary nailing of the humerus shaft fracture. Unfallchirurg 1994;97(8):424-9.

13. Durbin RA, Gottesman MJ, Saunders KC. Hackethal stacked nailing of humeral shaft fractures. Experience with 30 patients. Clin Orthop Relat Res 1983;(179):168-74.

14. Jensen $\mathrm{CH}$, Hansen D, Jørgensen U. Humeral shaft fractures treated by interlocking nailing: A preliminary report on 16 patients. Injury 1992;23(4):234-6.

15. Brumback RJ, Bosse MJ, Poka A, Burgess AR. Intramedullary stabilization of humeral shaft fractures in patients with multiple trauma. J Bone Joint Surg Am 1986;68(7):960-70.

16. Dabezies EJ, Banta CJ $2^{\text {nd }}$, Murphy CP, d'Ambrosia RD. Plate fixation of the humeral shaft for acute fractures, with and without radial nerve injuries. J Orthop Trauma 1992;6(1):10-3.

17. Marty B, Käch K, Candinas D, Friedl HP, Trentz O. Results of intramedullary nailing in humerus shaft fractures. Helv Chir Acta
1993;59(4):681-5.

18. Riemer BL, Butterfield SL, D’Ambrosia R, Kellam J. Seidel intramedullary nailing of humeral diaphyseal fractures: A preliminary report. Orthopedics 1991;14(3):239-46.

19. Vander Griend R, Tomasin J, Ward EF. Open reduction and internal fixation of humeral shaft fractures. Results using AO plating techniques. J Bone Joint Surg Am 1986;68(3):430-3.

20. Henley MB, Chapman JR, Claudi BF. Closed retrograde Hackethal nail stabilization of humeral shaft fractures. J Orthop Trauma 1992;6(1):18-24.

21. Hall RF Jr, Pankovich AM. Ender nailing of acute fractures of the humerus. A study of closed fixation by intramedullary nails without reaming. J Bone Joint Surg Am 1987;69(4):558-67.

22. Robinson CM, Bell KM, Court-Brown CM, McQueen MM. Locked nailing of humeral shaft fractures. Experience in Edinburgh over a two-year period. J Bone Joint Surg Br 1992;74(4):558-62.

23. Bell MJ, Beauchamp CG, Kellam JK, McMurtry RY. The results of plating humeral shaft fractures in patients with multiple injuries. The Sunnybrook experience. J Bone Joint Surg Br 1985;67(2):293-6.

24. Petsatodes G, Karataglis D, Papadopoulos P, Christoforides J, Gigis J, Pournaras J. Antegrade interlocking nailing of humeral shaft fractures. J Orthop Sci 2004;9(3):247-52.

25. Foster RJ, Dixon GL Jr, Bach AW, Appleyard RW, Green TM. Internal fixation of fractures and non-unions of the humeral shaft. Indications and results in a multi-center study. J Bone Joint Surg Am 1985;67(6):857-64.

26. Rodriguez-Merchan EC. Hackethal nailing in closed transverse humeral shaft fractures after failed manipulation. Int Orthop 1996;20(3):134-6.

27. Stern PJ, Mattingly DA, Pomeroy DL, Zenni EJ Jr, Kreig JK. Intramedullary fixation of humeral shaft fractures. J Bone Joint Surg Am 1984;66(5):639-46.

28. Babin SR, Graf P, North J, Schvingt E. Infection following closed intramedullary nailing by Kuntscher's method in 1059 fractures. Int Orthop 1981;5(4):271-6.

29. Ikpeme JO. Intramedullary interlocking nailing for humeral fractures: Experiences with the Russell-Taylor humeral nail. Injury 1994;25(7):447-55.

30. Kröpfl A, Naglik H, Niederwieser B, Hertz H. Unreamed antegrade humeral interlocking nailing. Unfallchirurg 2000;103(5):348-54. 